\title{
AVALIAÇÃO NUTRICIONAL E CONFORMIDADE DA ROTULAGEM DE "PETISCOS" CONSUMIDOS POR CRIANÇAS À LEGISLAÇÃO BRASILEIRA
}

\begin{abstract}
Márcia Regina Garcia ${ }^{1}$, Rogerio Vieites ${ }^{2}$ \& Erica Daiuto ${ }^{3}$
RESUMO: Rótulo é toda e qualquer informação referente a um produto que esteja transcrita em sua embalagem. Para o consumidor é por meio das tabelas de informação nutricional contidas nos rótulos que se tem acesso a dados como quantidade e porcentagem dos nutrientes presentes nos alimentos. Através desse conhecimento, pode-se realizar escolhas alimentares mais saudáveis, mitigando os efeitos negativos referentes à má nutrição na população, principalmente entre as crianças, alvo mais crítico da incidência da obesidade. $\mathrm{O}$ objetivo desta pesquisa foi avaliar a adequação dos rótulos de alguns alimentos consumidos pelo público infantil, em relação à Ingestão Diária Recomendada (IDR) e verificar se os aspectos gerais dos mesmos estavam em acordo com a legislação brasileira vigente. Para esse estudo foram selecionados cinco produtos embalados, tipo petiscos: salgadinho de milho, salgadinho de amendoim, amendoim, snacks de batata e biscoito de polvilho. Os rótulos de diferentes marcas de cada petisco foram analisados por meio da Ficha de Avaliação de Rotulagem, elaborada com base nas RDC N ${ }^{\circ} 259$, de 20 de setembro de 2002 e RDC $\mathrm{N}^{\circ}$ 360, de 23 de dezembro de 2003. A adequação nutricional dos nutrientes destes alimentos (carboidratos, proteínas, gordura total, gordura saturada, gordura trans, fibra alimentar e sódio) foi avaliada em relação à preconizada pela IDR para crianças de 4 a 8 anos de idade. Houve pequena porcentagem de erros nos rótulos dos alimentos analisados, cerca de $12 \%$, sendo a presença de vocábulos que induzem os consumidores ao equívoco a irregularidade com maior predominância, presente em $25 \%$ dos rótulos. Outros itens em desacordo foram a incompleta especificação dos aditivos alimentares na lista de ingredientes e a ausência de instruções sobre a conservação dos alimentos após abertura das embalagens, ambos com percentual de ocorrência de 18,75\%. O alto teor de sódio verificado na informação nutricional dos alimentos demonstra que deve-se mitigar o consumo destes produtos entre a população infantil.
\end{abstract}

PALAVRAS-CHAVE: obesidade infantil, rótulos, adequação nutricional.

Nutritional Evaluation And Compliance Labelling Of "Snacks" Consumed By Children To The Brazilian Regulations

\begin{abstract}
Label is every and any information regarding to a product that is transcribed in its package. For the consumer it is through the nutritional information tables contained in the labels that there is access to data such as quantity and percentage of nutrients contained in foods. Through this knowledge, it is possible to make healthier food choices, minimizing the negative effects related to poor nutrition in the population, especially among children, the most critical rate of obesity incidence. The aim of this study was to evaluate the appropriateness of the labels of some foods consumed by children in relation to the Recommended Daily Intake (RDI) and verify that the general aspects of the labels were in accordance with Brazilian regulations. Five products were selected like snacks, corn snacks, snacks, peanut, peanuts, potato snacks and biscuit recipes. The labels of different brands of each snack were analyzed using the Checklist of Labelling, which is based on RDC No. 259 and RDC No. 360. The nutritional adequacy of nutrients from these foods (carbohydrates, protein, total fat, saturated fat, trans fat, dietary fiber and sodium) was evaluated in relation to that recommended by the RDA for children 4-8 years old. There was small percentage of mistakes in the labels of the analyzed foods, about $12 \%$, being the presence of words that induce the consumers to the misunderstanding the irregularity with larger predominance, present in $25 \%$ of the labels. Other items in disagreement were the incomplete specification of the addictive ones alimentary in the list of ingredients and the absence of instructions about the conservation of the foods after opening the packings, both with percentile of occurrence of $18,75 \%$. The high sodium content found in the nutritional information of food shows that should reduce the consumption of these products among children.
\end{abstract}

KEYWORDS: Childhood obesity, labels, nutritional adequacy.

\footnotetext{
ETE Avare e Mestre pela FCA/UNESP. E-mail:

garcia.marcinha@gmail.com

${ }^{2}$ FCA/UNESP. E-mail: vieites@ fca.unesp.br

${ }^{3}$ Doutorado pela FCA/UNESP. E-mail: erdaiuto@uol.com.br
} 


\section{INTRODUÇÃO}

A prevalência de excesso de peso em crianças tem crescido em ritmo alarmante nos países em desenvolvimento, inclusive no Brasil, o que é preocupante visto que crianças obesas possuem grande chance de tornarem-se adultos obesos (ROSSI et al., 2010).

Tal situação pode ser atribuída, em parte, ao maior acesso a alimentos em quantidade excessiva e qualidade inadequada, ricos em gordura, carboidratos, sódio, etc., que, juntamente com a desinformação, induz a erros alimentares como o aumento do consumo de alimentos ricos em sódio, gorduras e açúcares, juntamente com deficiência de fibras e micronutrientes. Portanto, além da conscientização dos pais e educadores sobre esse aspecto, é importante verificar a presença destas substâncias nos rótulos dos alimentos.

A importância da rotulagem nutricional dos alimentos para a promoção da alimentação saudável é destacada em grande parte dos estudos e pesquisas que envolvem a área da nutrição e sua relação com estratégias para a redução do risco de doenças crônicas (COUTINHO; RECINE, 2007). Medidas legislativas, como é o caso das regulamentações sobre rotulação alimentar, são vistas como importantes atividades de promoção da saúde. O consumidor tem direito ao acesso às informações sobre as características e composição nutricional dos alimentos que adquire no comércio, ou seja, às suas propriedades nutricionais, para satisfazer suas necessidades alimentares.

A rotulagem dos alimentos, ao orientar o consumidor sobre a qualidade e a quantidade dos constituintes nutricionais dos produtos, pode promover escolhas alimentares apropriadas, sendo indispensável, no entanto, a fidedignidade das informações. No entanto, tem sido observado que as falhas na legislação vigente no Brasil propiciam o repasse de informações incorretas, que podem gerar confusão, principalmente no que tange à informação nutricional complementar (INC) e às normas sobre alimentos para fins especiais (CÂMARA et al., 2008).

A melhor instrução da população e a disponibilização de informações adequadas e compreensíveis sobre o conteúdo nutricional podem corrigir erros alimentares, contribuindo para a promoção da saúde e a redução do risco de doenças relacionadas à má nutrição e à alimentação inadequada na idade infantil.

Diante do exposto, o objetivo deste trabalho foi avaliar a adequação dos rótulos de alguns alimentos industrializados, denominados petiscos, consumidos pelo público infantil, em relação à Ingestão Diária Recomendada (IDR) e verificar se os aspectos gerais dos rótulos estavam em acordo com a legislação brasileira vigente.

\section{MATERIAL E MÉTODOS}

A pesquisa foi realizada em supermercados da cidade de Botucatu (SP) durante os meses de Fevereiro, Março e Abril de 2011. Foram selecionados cinco produtos embalados, tipo petisco, comumente consumidos pelo público infantil de acordo com Aquino e Philippi (2002) e POF (2008-2009), sendo adquiridos para posterior análise dos rótulos nutricionais.

Para cada produto foram analisadas diferentes marcas, conforme a disponibilidade, adquirindo-se um exemplar de cada marca, independentemente de outras formas produzidas (sabores ou embalagens diferentes) (Tabela 1).
Tabela 1 - Amostras coletadas de petiscos comumente consumidos pelo público infantil

\begin{tabular}{lcc}
\hline \multicolumn{1}{c}{ Produto } & Sabor/tipo & $\begin{array}{c}\mathbf{N}^{\circ} \text { de } \\
\text { marcas }\end{array}$ \\
\hline Salgadinho de milho & Queijo & 6 \\
\hline Salgadinho & Amendoim & 3 \\
\hline Amendoim & Japonês & 3 \\
\hline Snack frito & Batata & 5 \\
\hline Biscoito de polvilho & Salgado & 7 \\
\hline Total & & 24 \\
\hline
\end{tabular}

Para análise dos rótulos nutricionais formulou-se Ficha de Avaliação de Rotulagem. Esta foi elaborada com base nas seguintes Resoluções:

RDC 360/03 - Regulamento Técnico sobre Rotulagem Nutricional de Alimentos Embalados - que torna obrigatória a rotulagem nutricional baseada nas regras estabelecidas com o objetivo principal de atuar em benefício do consumidor e ainda evitar obstáculos técnicos ao comércio (BRASIL, 2003b).

RDC 359/03 - Regulamento Técnico de Porções de Alimentos Embalados para Fins de Rotulagem Nutricional - que estabeleceu que as porções indicadas nos rótulos de alimentos e bebidas embalados foram determinadas com base em uma dieta de 2000 Kcal considerando uma alimentação saudável e foram harmonizadas com os outros países do Mercosul (BRASIL, 2003a).

A Ficha de Avaliação de Rotulagem foi composta de duas tabelas com informações gerais de identificação dos produtos e de uma lista com treze questões mais detalhadas sobre os itens avaliados, para se comparar as informações dos rótulos com a Legislação (Quadro 1). 


\section{Quadro 1 - Ficha de avaliação de rotulagem.}

Ficha de Avaliação de Rotulagem: Informações Obrigatórias em Rótulos de Alimentos, baseada nas RDC n. 259 e RDC n. 360.

Alimento:

Marca:

$1 . \mathrm{O}$ rótulo do alimento apresenta vocábulos, sinais, denominações, símbolos, emblemas, ilustrações ou outras representações gráficas que possam tornar a identificação falsa, incorreta, insuficiente, ou que possa induzir o consumidor a equívoco, erro, confusão, ou engano, em relação à verdadeira natureza, composição, procedência, tipo, qualidade, quantidade, validade, rendimento ou forma de uso do alimento?

2.Possui denominação de venda do alimento escrita de forma correta?

A) Possui lista de ingredientes, sendo esta em ordem decrescente, da respectiva proporção?

B) Ingredientes compostos apresentam lista de ingredientes entre parênteses?

3.Caso o alimento possua aditivos alimentares:

a)Apresenta a função principal ou fundamental do aditivo no alimento?

b) Apresenta seu nome completo ou seu número INS?

c) Está declarado a lista de ingredientes?

4. Identificação de origem:

A) Existe identificação da origem completa discriminada no rótulo do alimento (nome ou razão social, endereço completo, país de origem e município, número de registro ou código de identificação do estabelecimento fabricante junto ao órgão competente)?

B) Para identificar a origem deve ser utilizada uma das seguintes expressões: "fabricado em...", "produto..." ou "indústria...". O rótulo apresenta de forma correta?

5.Se alimento importado, possui nome ou razão social e endereço do importador?

6. Possui identificação do lote visível, legível e indelével?

7.Apresenta prazo de validade de forma clara e precisa?

* Para produtos como balas, caramelos, confeitos, goma de mascar, pastilhas e similares, não é obrigatório a identificação do prazo de validade.

8. No caso de alimentos que exijam condições especiais de conservação ou alimentos que podem se alterar depois de abertas as suas embalagens, deve ser incluída legenda com caracteres bem legíveis, indicando as precauções necessárias para manter suas características normais. Isto está presente no rótulo?

9.Se necessário, possui instruções sobre o preparo e uso do alimento?

10.Possui porção discriminada em gramas ou mililitros e subsequente medida caseira referente a esta porção alimentar?

11. A tabela de informação nutricional apresenta-se de forma completa*?

*Informação nutricional completa: valor energético, quantidade de carboidratos, proteínas, gorduras totais, gorduras saturadas, gorduras trans, fibra alimentar, sódio, outros minerais e vitaminas (quando declarados), sendo estes valores por porção alimentar e porcentagem de valor diário (\%VD).

Caso a informação não esteja completa, qual ou quais itens estão faltando?

12.No painel principal está presente a denominação de venda do alimento, assim como a quantidade nominal do conteúdo do produto de forma visível?

13.O rótulo possui letras ou números com tamanho inferior a $1 \mathrm{~mm}$, exceto conteúdo líquido?

Os dados foram primeiramente transcritos para a Ficha de Avaliação de Rotulagem para comparação com os padrões da ANVISA, observando se houve ou não discrepâncias. Quando se encontrava erro, esse era anotado para contabilização posterior.

Paralelamente, analisou-se a Tabela de Informação Nutricional dos rótulos dos alimentos para verificar sua adequação em relação à IDR (IOM, 2002) para crianças de 4 a 8 anos de idade. Para tanto, comparou-se os itens de declaração obrigatória: carboidratos em gramas, proteínas em gramas, gorduras totais em gramas, gorduras saturadas em gramas, gorduras trans em gramas, fibra alimentar em gramas e sódio em miligramas com os dados de ingestão recomendada. Também foi verificado o percentual do Valor Diário de Referência (\%VDR) para os itens supracitados, os quais estão baseados em uma dieta de $2000 \mathrm{kcal}$, a fim de investigar sua adequação com a dieta para crianças. Considerou-se nesse trabalho que os dados nutricionais apresentados nos rótulos dos produtos analisados foram mensurados corretamente através de métodos validados.

\section{Estatística}

Foi utilizada a análise de agrupamento, método hierárquico, sendo que o algoritmo de agrupamento utilizado foi o do vizinho mais próximo e o coeficiente de associação de Jaccard. $\mathrm{O}$ ponto de corte do dendrograma para definir o número de grupos fundamentou-se na técnica apresentada por Corrar et al. (2009) em que o ponto de corte ocorre no momento em que a distância reescalonada do coeficiente de aglomeração apresenta a maior variação. 


\section{RESULTADOS E DISCUSSÃO}

A análise de agrupamentos permitiu a formação de dois grupos (Figura 2).

Os alimentos presentes no primeiro grupo foram: biscoitos de polvilho das marcas D, F, E, A, B e G; amendoim tipo japonês da marca $\mathrm{C}$; batata frita da marca A.

Nos biscoitos de polvilho das marcas D, E e F não havia uma das seguintes expressões "fabricado em...", "produto..." ou "indústria..." para identificação de suas origens. O biscoito $\mathrm{D}$ também não possuía número do lote de forma visível e indelével.

Já o amendoim da marca $\mathrm{C}$ não descriminou entre parênteses em sua lista de ingredientes os itens compostos, ou seja, faltou especificar mais detalhadamente os ingredientes utilizados em sua fabricação.

O segundo grupo foi formado pelos seguintes produtos: batatas fritas $\mathrm{B}$ e $\mathrm{C}$; salgadinhos de batata das marcas $\mathrm{A}$ e B, salgadinhos de milho das marcas C, D, A, F, B e E; salgadinhos de amendoim das marcas A, B e C; amendoins tipo japonês das marcas A e B; biscoito de polvilho da marca $\mathrm{C}$.

Observou-se nesse grupo a presença de expressões como "livre de colesterol", "fonte de fibras" e "alimento assado" no salgadinho de batata A, nos salgadinhos de milho das marcas $\mathrm{C}$ e D e na batata frita da marca C. Ao utilizar a frase "livre de colesterol" o fabricante deveria esclarecer ao consumidor que, assim como os demais salgadinhos de batata, seu produto não contem colesterol. O uso do termo "fonte de fibras" deveria ser substituído por "alimento enriquecido de fibras" no caso do salgadinho de milho D, conforme a RDC $\mathrm{n}^{\circ} 259$ da ANVISA (2002), na qual somente podem ser utilizadas denominações de qualidade quando tenham sido estabelecidas as especificações correspondentes para um determinado alimento, por meio de Regulamento Técncio específico e que seja facilmente compreensíveis, não devendo de forma alguma levar o consumidor a equívocos ou enganos.

Ademais a divergência supracitada, a batata frita da marca $\mathrm{C}$ e o salgadinho de batata da marca A também apresentaram falhas nas denominações de venda de seus produtos. Para a batata frita este item estava ausente em seu rótulo e no caso do salgadinho encontrava-se escrito de forma incompleta.

O salgadinho de milho da marca $\mathrm{D}$ não descreve na lista de ingredientes a formulação do condimento preparado sabor cebola, dificultando o acesso à informação do consumidor quanto aos ingredientes presentes no alimento. Os produtos amendoim tipo japonês da marca A, salgadinho de amendoim da marca B e os salgadinhos de milho das marcas B e C não especificaram os tipos de aromatizantes utilizados em suas preparações.

A incompleta identificação da origem foi verificada nos produtos salgadinho de amendoim $\mathrm{B}$, batata frita $\mathrm{B}$ e salgadinhos de milho A e C ao não utilizarem expressões como "fabricado em...", "produto..." ou "indústria..." em seus rótulos. Quanto à identificação do lote, os produtos salgadinho de milho A e salgadinho de amendoim A, não apresentavam este item de forma visível, legível e indelével. Outro problema verificado no rótulo do salgadinho de amendoim A foi a ausência, de forma clara e precisa, de sua data de validade e das orientações quanto à conservação do produto após sua abertura. Este item estava ausente também no salgadinho de milho D e no salgadinho de batata $B$.

O biscoito de polvilho da marca $\mathrm{C}$ não apresentou os itens: lista de ingredientes em ordem decrescente em quantidade utilizada para fabricação do produto e identificação de origem do fabricante e lote no rótulo.

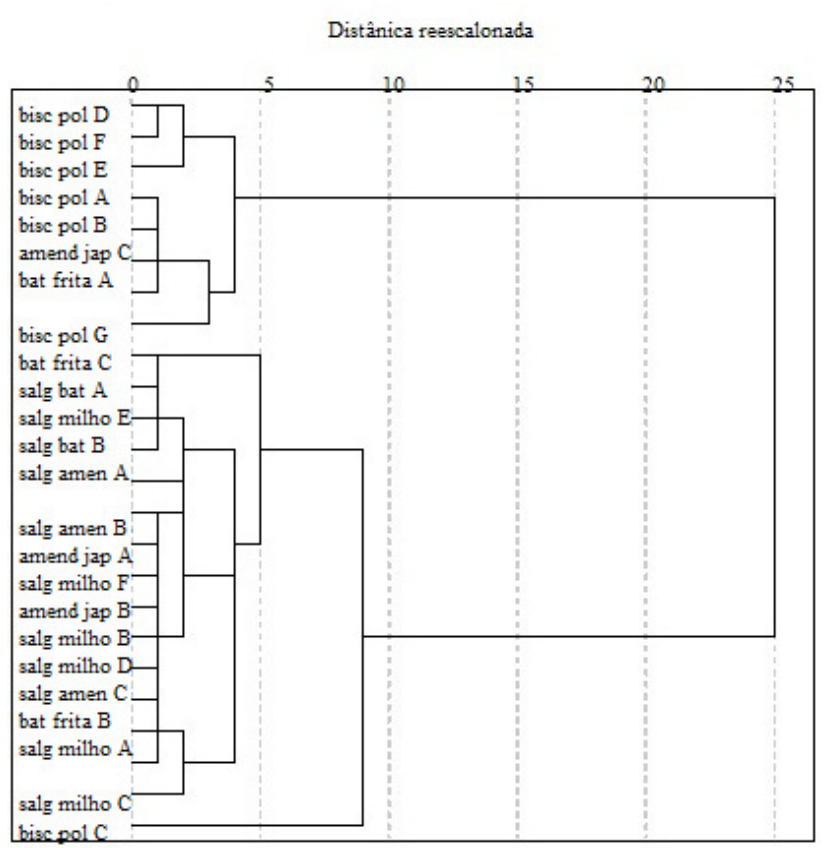

Figura 2 - Dendrograma formado por petiscos consumidos pelo público infantil.

Estes produtos foram avaliados em relação aos seus dados nutricionais. A rotulagem nutricional é toda inscrição destinada a informar ao consumidor sobre as propriedades nutricionais dos alimentos (ANVISA, 2005). Foram analisadas as tabelas de informação nutricional dos produtos a fim de verificar sua adequação às necessidades infantis diárias de acordo com o IOM (2002) dos nutrientes cuja declaração é obrigatória: carboidratos; gorduras totais, saturadas e trans; proteínas; fibra alimentar e sódio, discutindo-se os nutrientes cujos teores apresentaram relevância para alimentação infantil.

Os salgadinhos de milho apresentam textura altamente apreciada pelo publico infantil e para tornarem-se mais palatáveis e aceitáveis para o consumo, estes produtos são adicionados de aromatizantes. O sabor e o aroma fixam-se no salgadinho através de um veículo lipídico, normalmente gordura vegetal hidrogenada, elevando os índices de gordura saturada e de ácidos graxos trans em sua composição (CAPRILES; ARÊAS, 2005). 
Dentre as seis marcas de salgadinhos de milho analisadas, a que apresentou menor teor de gordura total em sua composição foi a do salgadinho de milho da marca $\mathrm{F}$, com $1,69 \mathrm{~g}$ de gordura por porção de alimento $(25 \mathrm{~g})$, conforme demonstrado na Figura 3.

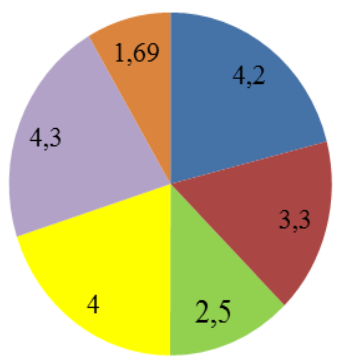

- salgadinho milho A

- salgadinho milho B

a salgadinho milho $\mathrm{C}$

salgadinho milho D

salgadinho milho $\mathrm{E}$

salgadinho milho $\mathrm{F}$

\section{Figura 3 - Valor de gordura total em gramas por porção dos salgadinhos de milho.}

A fritura é uma operação importante no preparo dos salgadinhos de batata, conferindo-lhes características únicas de sabor e odor. Este processo, porém, modifica a composição nutricional do alimento, pois ocorre absorção de óleo, aumentando o teor lipídico do produto ao final de sua fabricação (DAMY; JORGE, 2003). Verificou-se maior quantidade de gordura total por porção de alimento $(25 \mathrm{~g})$ entre os salgadinhos de batata e batatas fritas em relação aos salgadinhos de milho. A média de gordura total nos produtos de batata foi de $8,45 \mathrm{~g}$ e o produto que apresentou maior valor foi a batata frita da marca C, com $10 \mathrm{~g}$ de gordura total por porção do alimento (Figura 4).

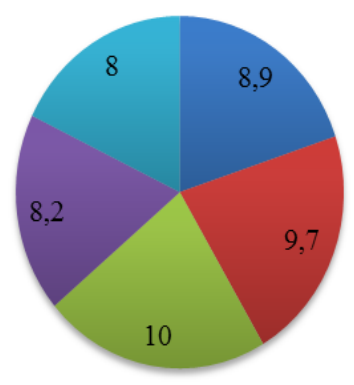

watata frita $\mathrm{A}$

- batata frita B

watata frita $\mathrm{C}$

- salgadinho batata A

- salgadinho batata $\mathrm{B}$ Figura 4 - Valor de gordura total em gramas por
porção dos salgadinhos de batata.

Outro nutriente encontrado em quantidade excessiva nos salgadinhos de milho e de batata é o sódio. Entre os salgadinhos de milho, observou-se maior porcentagem de sódio na marca D com $29,17 \%$ das necessidades diárias infantis (IOM, 2002) por porção do alimento. Ao se comparar a mesma porção de $25 \mathrm{~g}$ de alimento, os salgadinhos de batata fornecem, em média, $11,25 \%$ das necessidades diárias de sódio, porcentagem menor que a média observada nos salgadinhos de milho (12,31\%) (Figura 5).

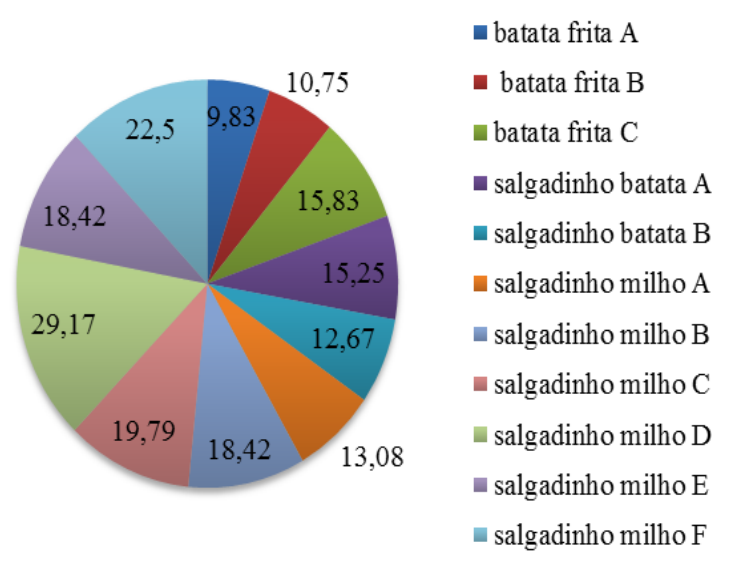

Figura 5 - Porcentagem de sódio por porção dos salgadinhos de milho e salgadinhos de batata.

Com relação à fibra alimentar, o salgadinho da marca $\mathrm{E}$ pode ser considerado contendo alto teor de fibra alimentar, apresentando $7 \mathrm{~g}$ em $100 \mathrm{~g}$ de alimento (ANVISA, 2005), maior porcentagem dentre os alimentos analisados (Figura 6).

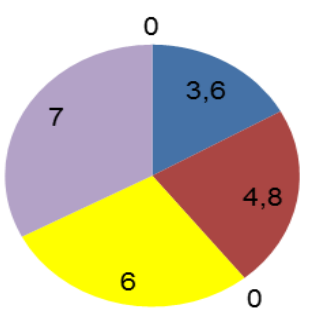

ש salgadinho milho A
— salgadinho milho B
— salgadinho milho C
salgadinho milho D
- salgadinho milho E
- salgadinho milho F Figura 6 - Porcentagem de fibra alimentar por
porção dos salgadinhos de milho.

Os biscoitos que fazem uso da fécula de mandioca em seu estado natural ou fermentado (polvilho azedo) são um típico produto brasileiro, comumente chamados de biscoitos de polvilho. Tradicionalmente, eram produzidos em padarias, mas, atualmente, muitas empresas também os fabricam (MONTENEGRO et al., 2008). Porém, trata-se de um produto de baixo valor agregado, pobre em fibras e minerais (CAMARGO; LEONEL; MISCHAN, 2008).

Dentre as marcas analisadas, notou-se diferença entre os percentuais de sódio, sendo que o menor valor foi encontrado no biscoito de polvilho da marca $\mathrm{C}$, com $2,08 \%$ das necessidades diárias infantis, e o maior valor no produto da marca E, com $34,8 \%$ das necessidades por porção (20g) (IOM, 2002) (Figura 7). 


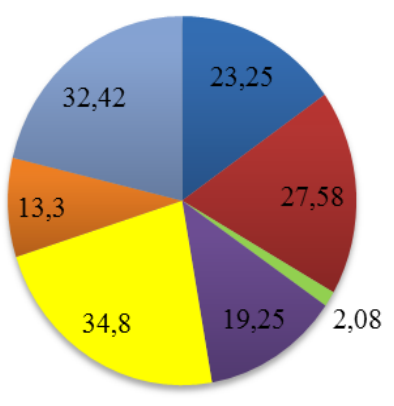

- biscoito polvilho A

- biscoito polvilho B

biscoito polvilho $\mathrm{C}$

- biscoito polvilho D

biscoito polvilho $\mathrm{E}$

biscoito polvilho $\mathrm{F}$

- biscoito polvilho $\mathrm{G}$

\section{Figura 7 - Porcentagem de sódio por porção em biscoitos de polvilho.}

Nos produtos ovinhos de amendoim e amendoim tipo japonês, houve alta porcentagem de sódio e gordura presente nesses alimentos. Conforme observa-se na Figura 8, o ovinho de amendoim da marca A fornece em $15 \mathrm{~g}$ (porção do produto) $31,25 \%$ das necessidades diárias de sódio para crianças de 4 a 8 anos de idade (IOM, 2002). Para o amendoim tipo japonês, destaca-se $\mathrm{o}$ alto teor de gordura total presente no alimento, a porção de $15 \mathrm{~g}$ contem, em média, $6,9 \mathrm{~g}$ deste nutriente.

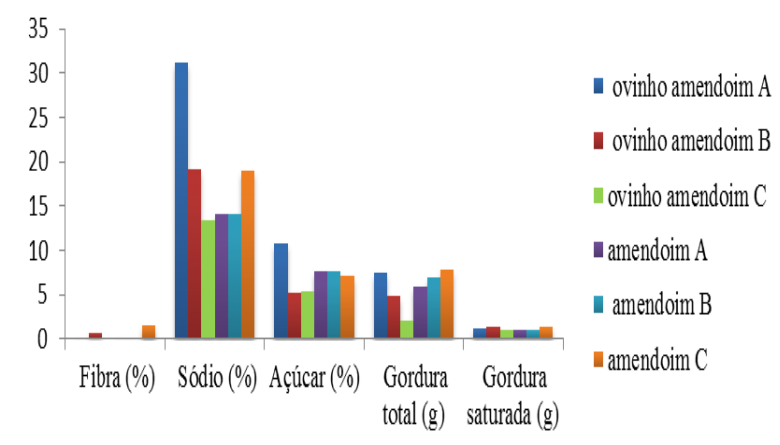

\section{Figura 8 - Composição nutricional de ovinhos de amendoim e de amendoim tipo japonês.}

Ribeiro et al. (2013) realizaram estudo para determinar o teor de sódio em alimentos processados voltados para crianças e adolescentes e averiguar a adequação do teor encontrado em relação aos níveis de ingestão dietética de referência, verificando também a conformidade das informações veiculadas na rotulagem. Os autores avaliaram

17 amostras (massa instantânea, empanado, hambúrguer, salsicha e mortadela) pela fotometria de chama e determinação de cloretos por volumetria e os resultados foram comparados aos dados das informações nutricionais. A conformidade da rotulagem foi verificada a partir das legislações pertinentes. Houve variação maior que $20 \%$ entre o teor de sódio analisado e o declarado em 13 produtos pela fotometria de chama, e em 5, pela volumetria. Todas as amostras apresentaram mais de 480mg de sódio/porção e o limite de ingestão adequada para crianças de 4 a 8 anos foi ultrapassado, pela fotometria, nas 8 massas instantâneas e em 3 empanados. Pela volumetria, a oferta de sódio ultrapassa os níveis de ingestão recomendados para crianças entre 4 e 8 anos em 9 amostras analisadas.

\section{CONCLUSÃO}

Em suma, pode-se concluir que houve pequena porcentagem de erros nos rótulos dos alimentos analisados, cerca de $12 \%$, sendo a presença de vocábulos que induzem os consumidores ao equívoco a irregularidade com maior predominância, presente em $25 \%$ dos rótulos. Outros itens em desacordo foram a incompleta especificação dos aditivos alimentares na lista de ingredientes e a ausência de instruções sobre a conservação dos alimentos após abertura das embalagens, ambos com percentual de ocorrência de $18,75 \%$. Quanto ao valor nutricional, estes alimentos apresentaram alto teor de sódio, portanto, seu consumo deve ser evitado entre as crianças.

Sendo assim, verifica-se que, apesar da legislação brasileira de rotulagem de alimentos ser abrangente e servir de exemplo para outros países, há ainda a necessidade de maior fiscalização para cumprimento das normas estabelecidas.

\section{REFFERENCIAS}

\section{AGÊNCIA NACIONAL DE VIGILÂNCIA}

SANITÁRIA (ANVISA). Alimentos. Rótulos de alimentos: manual de orientação ao consumidor. 2005.

Disponível em

www.anvisa.gov.br/alimentos//rotulso/manual_consumid or.pdf [Acesso em 01 de Fevereiro de 2012].

AQUINO, R. S.; PHILIPPI, S. T. Consumo infantil de alimentos industrializados e renda familiar na cidade de São Paulo. Revista Saúde Pública, São Paulo, v. 6, n. 36, p. 655-660, 2002.

BRASIL. Resolução RDC n ${ }^{\circ} 359$, de 23 de Dezembro de 2003. Aprova regulamento técnico de porções de alimentos embalados para fins de rotulagem nutricional. Diário Oficial da União. 26 de dez 2003a; Seção 1:28.

BRASIL. Resolução RDC n 360, de 23 de Dezembro de 2003. Aprova regulamento técnico sobre rotulagem nutricional de alimentos embalados, tornando obrigatória a rotulagem nutricional. Diário Oficial da União. 26 de dez 2003b; Seção 1:

CÂMARA, M. C. C. et al. A produção acadêmica sobre a rotulagem de alimentos no Brasil. Revista

Panamericana de Salud Publica, Washigton, v. 23, n. 1, p. 52-58, 2008.

CAMARGO, K. F.; LEONEL, M.; MISCHAN, M. M. Produção de biscoitos extrusados de polvilho azedo com fibras: efeito de parâmetros operacionais sobre as propriedades físicas. Revista Ciência e Tecnologia de Alimentos, Campinas, v. 28, n. 3, p. 586-591, 2008.

CAPRILES, V. D.; ARÊAS, J. A. G. Desenvolvimento de salgadinhos com teores reduzidos de gordura saturada e de ácidos graxos trans. Revista Ciência e Tecnologia de Alimentos, Campinas, v. 25, n. 2, p. 363-369, 2005.

CORRAR, L.J.; PAULO, E.; DIAS FILHO, J.M. 
Análise multivariada para os cursos de administração, ciências contábeis e economia. 1 ed. 2 . reimp. São Paulo: Atlas, 2009. 541 p.

COUTINHO, J. G.; RECINE, E. Experiências internacionais de regulamentação das alegações de saúde em rótulos de alimentos. RevistaPanamericana de Salud Publica, Washigton, v. 22, n. 6, p. 432-437, 2007.

DAMY, P. C.; JORGE, N. Absorção de óleo de soja refinado e gordura vegetal hidrogenada durante o processo de fritura descontínua de batata chips. Revista Alimentos e Nutrição, Araraquara, v. 14, n. 1, p. 23-26, 2003.

INSTITUTE OF MEDICINE (IOM). Dietaryintake 2001/2002. Disponível em

www.iom.edu/Object.File/Master/21/372/0.pdf [Acesso em 25 de Janeiro de 2012].

MONTENEGRO, F. M. et al. Biscoitos de polvilho azedo enriquecidos com fibras solúveis e insolúveis. Revista Ciência e Tecnologia de Alimentos, Campinas, v. 28, n. 1, p. 184-191, 2008.

PESQUISA DE ORÇAMENTOS FAMILIARES (POF) 2008-2009. Análise de consumo alimentar pessoal no Brasil. Disponível em www.ibge.gov.br/estatistica/condicaodevida/pof/20082009. [Acesso em 24 de Maio de 2012].

RIBIERO, V.F., RIEIRO, M.A., VASCONCELOS, ANDRADE, S.A.C., STAMFORD, T.L.M. Processed foods aimed at childrem and adolescents: Sodium content, adequacy according to dietary reference intakes and label compliance. Revista Nutrição, Campinas, v.26, n.4, p.397-406, 2013.

ROSSI, C. E. et al. Influência da televisão no consumo alimentar e na obesidade em crianças e adolescentes: uma revisão sistemática. Revista de Nutrição, Campinas, v. 23, n. 4, p. 607-620, 2010. 